\title{
Faktor-Faktor Yang Berhubungan dengan Gejala Neurotoksik Akibat Paparan Pestisida pada Petani Sayuran di Kenagarian Alahan Panjang Kabupaten Solok
}

\author{
Aria Gusti' ${ }^{1}$ Ira Desnizar ${ }^{2}$ \\ ${ }^{1}$ Departemen Kesehatan Lingkungan, Fakultas KesehatanMasyarakat, Universitas Andalas \\ ${ }^{2}$ Program Studi Ilmu Kesehatan Masyarakat, Fakultas Kesehatan Masyarakat, Universitas Andalas \\ Info Artikel : Diterima Februari 2017 ; Disetujui Februari 2017 ; Publikasi April 2017
}

\begin{abstract}
ABSTRAK
Latar belakang: Sekitar $60 \%$ petani penyemprot sayur di Kanagarian Alahan Panjang mempunyai riwayat gejala neurotoksik. Penelitian ini bertujuan untuk mengkaji faktor-faktor yang berhubungan dengan gejala gangguan syaraf pada petani penyemprot yang menggunakan pestisida di Kanagarian Alahan Panjang Kabupaten Solok.

Metode: Penelitian ini merupakan penelitian observasional dengan rancangan cross-sectional. Subyek penelitian sebanyak 75 responden. Penarikan sampel dilakukan secara random. Variabel yang dikaji dalam penelitian ini meliputi jenis pestisida, komposisi pestisida, pemakaian alat pelindung diri, dan gejala neurotoksik. Instrument penelitian menggunakan kuesioner Q18 versi Jerman. Analisis data menggunakan uji Chi-square pada taraf signifikasi 5\%.

Hasil: Hasil penelitian menunjukkan sebanyak $62,7 \%$ petani penyemprot sayuran pernah mengalami gejala neurotoksik. Hasil analisis statistik menunjukkan ada hubungan signifikan antara jumlah dan komposisi pestisida yang digunakan dengan gangguan neurotoksik pada petani sayuran ( $\mathrm{p}$-value $<0,05$ ). Sedang kebiasaan pemakaian alat pelindung diri tidak berpengaruh terhadap kejadian gangguan neorotoksik.

Simpulan: Jumlah dan komposisi pestisida berhubungan secara signifikan dengan gangguan neurotoksik pada petani sayuran di Kanagarian Alahan Kabupaten Solok. Petani sayur disarankan untuk mengganti pestisida organofosfat dengan pestisida yang tidak berbahaya untuk kesehatan seperti pirethroid. Petani sayur disarankan untuk mengunakan alat pelindung diri pada aktivitas pencampuran dan penyemprotan pestisida.
\end{abstract}

Kata kunci: Gejala neurotoksik; pestisida; petani sayuran; Solok.

\section{ABSTRACT}

Title: Factors Related to Neurotoxic Symptoms on Pesticides Exposed Vegetable Farmer in Kanagarian Alahan Panjang, Solok District

Background: Around 60\% of vegetable farmer sprayer in Kenagarian Alahan Panjang have experienced of the neurotoxic symptoms. The purpose of this study was to determine factors associated with neurotoxic symptoms on vegetable farmer sprayer with pesticide in Kenagarian Alahan Panjang Solok District in 2016.

Method: Type of this research was quantitative using cross-sectional design. The sample were 75 respondents. Sampling using simple random sampling technique. Processing data using univariate and bivariate analysis with chi-square test.

Result: The result of this research showed $(62,7 \%)$ vegetable farmer sprayer have experienced of the neurotoxic symptoms. Bivariate analysis showed there were significant relationship $(p<0,05)$ between pesticide composition and amount of pesticide with neurotoxic symptoms. There was no significant relationship between use of personal protective equipment with neurotoxic symptoms.

Conclusion: The number and compostion of pesticides were factors which had associated significantly with neurotoxic symptoms. It was suggested to vegetable farmers to change organofosfat pesticide which was not 
dangerous to health like faction of pyrethroids. Vegetable farmers were suggested to use appliance protector of $X$ 'self completely when activity of mixing and application of pesticide.

Key words : Neurotoxic symptoms; Pesticide; Vegetable farmer; Solok.

\section{PENDAHULUAN}

Pestisida secara umum diartikan sebagai bahan kimia beracun yang digunakan untuk mengendalikan jasad pengganggu yang merugikan manusia. Dalam sejarah peradaban manusia, pestisida telah cukup lama digunakan di bidang kesehatan (bidang pemukiman dan rumah tangga) dan terutama dalam bidang pertanian. ${ }^{1}$

Pada sektor pertanian, penggunaan pestisida secara tidak langsung berdampak penting pada peningkatan hasil pertanian. Namun demikian, pengunaan pestisida secara terus menerus justru mengakibatkan pencemaran pada tanah pertanian. Selain terhadap lingkungan, penggunaan pestisida juga berdampak langsung pada kesehatan manusia, salah satunya adalah dapat menimbulkan efek neurobehavioral (NB) atau lebih dikenal dengan gejala neurotoksik. ${ }^{2}$

Gejala neurotoksik didefenisikan sebagai perubahan yang merugikan atau gangguan secara fungsional pada saraf, baik sistem saraf pusat maupun sistem saraf tepi yang diakibatkan oleh paparan bahan kimia, agent fisik maupun biologis yang lebih dikenal dengan zat neurotoksik atau neurotoksikan. Gangguan ini mengakibatkan perubahan pada memori, perhatian, suasan hati, disorientasi, penyimpangan berfikir, serta perubahan somatik, sensorik, dan fungsi kognitif sebagai efek neurotoksik akibat penggunaan neurotoksikan.

Penggunaan pestisida secara global mencapai 3,5 juta ton per tahun. Penggunaan pestisida yang cukup besar ini memberikan dampak besar terhadap kesehatan seperti terjadinya gejala neurotoksik. Gejala neurotoksik atau termasuk kedalam sepuluh penyakit terbanyak yang berhubungan dengan tempat kerja di Amerika Serikat. Pajanan terhadap zat racun seperti timbal, pestisida, pelarut organik dan insektisida di tempat kerja dianggap berkontribusi dalam perkembangan terjadinya gejala neurotoksik. ${ }^{3}$

Kenagarian Alahan Panjang dikenal dengan hasil pertanian berupa sayuran-sayuran dan buah-buahan yang melimpah. Nagari yang berjarak sekitar $71 \mathrm{~km}$ dari Kota Padang tepatnya berada di lereng timur kawasan Taman Nasional Kerinci Seblat. Nagari yang dikenal sebagai sentra sayuran terbesar di Sumatera Barat ini beresiko tinggi terhadap pencemaran akibat penggunaan pestisida. Pada tahun 2014, volume penjualan pestisida di daerah ini mencapai 57 ton. Penggunaan pestisida yang cukup besar ini dapat menimbulkan berbagai dampak terhadap kesehatan salah satunya adalah timbulnya gejala neurotoksik.

Berdasarkan fakta-fakta di atas, maka pertanyaan yang diajukan dalam penelitian ini adalah: "Faktor apa saja yang berhubungan dengan gejala neurotoksik pada petani penyemprot tanaman sayuran dengan pestisida di Kenagarian Alahan Panjang Kabupaten Solok?

Penelitian Wasseling mengenai gejala neurotoksik pada petani pisang menyatakan bahwa sebanyak 81 orang yang teridentifikasi keracunan akut pestisida organofosfat mengalami gejala neurotoksik. ${ }^{4}$ Sejalan dengan penelitian yang dilakukan Rothlein mengenai gejala neurotoksik terhadap 45 pekerja pertanian dan 45 pekerja non pertanian menyimpulkan bahwa pekerja pertanian memiliki performa NB yang buruk dibandingkan dengan pekerja non pertanian. ${ }^{5}$

Asosiasi Industri Perlindungan Tanaman Indonesia (AIPTI) mengemukakan dari 1.000 petani hanya $1 \%$ petani yang menerapkan pola pemakaian pestisida secara benar. Penerapan pemakaian pestisida yang tidak benar inilah yang nantinya menyebabkan terjadinya berbagai gangguan kesehatan, hingga terjadinya gangguan neurotoksik. Penelitian Zainul mengenai gejala neurotoksik dan faktor determinannya pada petani penyemprot tanaman sayur dengan pestisida di Desa Perbawati Kabupaten Sukabumi menyimpulkan $60,6 \%$ petani mengalami efek NB. ${ }^{6}$

Kenagarian Alahan Panjang merupakan salah satu kenagarian yang terletak di Kecamatan Lembah Gumanti Sumatera Barat.

\section{MATERI DAN METODE}

Penelitian ini merupakan penelitian analitik observasional dengan desain cross sectional. Penelitian ini dilakukan di Kenagarian Alahan Panjang Kecamatan Lembah Gumanti Kabupaten Solok, pada bulan Februari sampai April 2016. Populasi penelitian ini adalah petani penyemprot tanaman sayuran yang menggunakan pestisida di Kenagarian Alahan Panjang Kecamatan Lembah Gumanti Kabupaten Solok. Sebanyak 75 responden dipilih secara acak dari populasi penelitian. Data penelitian diperoleh dari data sekunder dan primer. Data sekunder diperoleh dari UPTD Penyuluhan Pertanian dan Perikanan yaitu data tentang jumlah kelompok tani. Data primer mengenai jenis pestisida, komposisi pestisidadan pemakaian alat pelindung diri (APD) diperoleh dari hasil kuesioner variabel independen dan data mengenai gejala neurotoksik diperoleh dari kuesioner Q18 versi Jerman. Analisis statistic menggunakan uji kai kuadrat dengan derajat kepercayaan 95\% dan kemaknaan 5\%.

\section{HASIL DAN PEMBAHASAN}

Penelitian ini bertujuan untuk menentukan hubungan antara jenis pestisida, komposisi pestisidadan pemakaian APD dengan kejadian 
gangguan neurotoksik pada petani penyemprot pestisida di Kenagarian Alahan Panjang, Solok

Tabel 1. Gejala Neurotoksik pada Petani Penyemprot Sayuran di Kenagarian Alahan Panjang, Solok berdasarkan Kuesioner Q18 Versi Jerman

\begin{tabular}{|c|c|c|c|}
\hline No & Pertanyaan & Ya & Tidak \\
\hline 1 & Apakah Anda merasa pelupa pada hal yang baru saja terjadi? & $42(56,0 \%)$ & $33(44,0 \%)$ \\
\hline 2 & $\begin{array}{l}\text { Apakah ada keluargaAnda yang mengatakan Anda sering lupa pada hal } \\
\text { yang baru saja terjadi? }\end{array}$ & $27(36,0 \%)$ & $48(64,0 \%)$ \\
\hline 3 & $\begin{array}{l}\text { Apakah Anda sering harus mencatat tentang hal-hal yang tidak boleh } \\
\text { Anda lupakan? }\end{array}$ & $2(2,7 \%)$ & $73(97,3 \%)$ \\
\hline 4 & $\begin{array}{l}\text { Apakah Anda secara umum menemukan kesulitan mengerti isi surat } \\
\text { kabar dan buku? }\end{array}$ & $3(4,0 \%)$ & $72(96,0 \%)$ \\
\hline 5 & Apakah Anda sulit berkonsentrasi? & $42(56,0 \%)$ & $33(44,0 \%)$ \\
\hline 6 & $\begin{array}{l}\text { Apakah Anda sering merasa mudah marah/ emosi tanpa sebab yang } \\
\text { jelas? }\end{array}$ & $5(6,7 \%)$ & $70(93,3 \%)$ \\
\hline 7 & Apakah Anda sering merasa sedih/depresi tanpaalasan yang jelas? & $1(1,3 \%)$ & $74(98,7 \%)$ \\
\hline 8 & Apakah Anda sering merasa lelah berlebihan di luar kebiasaan? & $30(40,0 \%)$ & $45(60,0 \%)$ \\
\hline 9 & $\begin{array}{l}\text { Pernahkah Anda merasakan jantung berdebar tanpa adanya tekanan/ } \\
\text { melakukan apapun? }\end{array}$ & $48(64,0 \%)$ & $27(36,0 \%)$ \\
\hline 10 & Apakah Anda sering merasa sakit/ sesak seperti ditekan di dada? & $46(61,3 \%)$ & $29(38,7 \%)$ \\
\hline 11 & Apakah Anda berkeringat tanpa sebab yang jelas? & $31(41,3 \%)$ & $44(58,7 \%)$ \\
\hline 12 & $\begin{array}{l}\text { Apakah Anda sering mengalami sakit kepalasekali dalam seminggu atau } \\
\text { lebih? }\end{array}$ & $25(33,3 \%)$ & $50(66,7 \%)$ \\
\hline 13 & Apakah keinginan seksualitas Anda berkurang dari pada biasanya? & $14(18,7 \%)$ & $61(81,3 \%)$ \\
\hline 14 & Apakah Anda sering merasa tidak sehat? & $37(49,3 \%)$ & $38(50,7 \%)$ \\
\hline 15 & Apakah Anda sering merasakan kebal/ baal pada tangan/ kaki Anda? & $52(69,3 \%)$ & $22(29,3 \%)$ \\
\hline 16 & Apakah ada rasa lemas/ lemah pada lengan/ tungkai kaki Anda? & $28(37,3 \%)$ & $47(62,7 \%)$ \\
\hline 17 & Apakah tangan Anda sering bergetar (tremor)? & $39(52,0 \%)$ & $36(48,0 \%)$ \\
\hline 18 & Apakah Anda tidak terbiasa dengan minuman beralkohol? & $0(0 \%)$ & $75(100 \%)$ \\
\hline
\end{tabular}

\section{GejalaNeurotoksik}

Dari hasil pengumpulan data dengan kuesioner Q18 diketahui bahwa sebanyak 47 responden $(62,7 \%)$ mengalami gejala neurotoksik. Gejala neurotoksik terbanyak yang dirasakan adalah sering merasakan kebal/ baal pada tangan dan kaki yaitu sebanyak (69,3\%), sering merasakan jantung berdebar tanpa adanya tekanan/melakukan apapun yaitu sebanyak
$(64,0 \%)$, sering merasakan sakit/ sesak seperti ditekan di dada yaitu sebanyak $(61,3 \%)$, sulit berkonsentrasi yaitu sebanyak $(56,0 \%)$, serta merasa 70 pelupa pada hal yang baru saja terjadi $(56,0 \%)$. Tabel 1 memperlihatkan secara lebih rinci gejala yang dirasakan responden berdasarkan pertanyaan yang diajukan dalam kuesioner Q18 versi Jerman

Tabel 2. Hubungan Jenis Pestisida, Komposisi Pestisida, dan Pemakaian APD dengan Gangguan Neurotoksik

\begin{tabular}{lcccc}
\hline \multirow{2}{*}{ Variabel } & \multicolumn{2}{c}{ Gangguan Neurotoksik } & \multirow{2}{*}{ Total } & p-value \\
\cline { 2 - 3 } & Ada Gejala & Tidak Ada Gejala & & \\
Jenis pestisida & $40(74,1 \%)$ & $14(25,9 \%)$ & 54 & 0,002 \\
- Organofosfat & $7(33,3)$ & $14(66,7 \%)$ & 21 & \\
- Non organofosfat & & & & 0,000 \\
Komposis i pestisida & $46(70,8 \%)$ & $19(29,2 \%)$ & 65 & 0,157 \\
- Campuran & $1(10,0 \%)$ & $9(90 \%)$ & 10 & \\
- Tunggal & $37(68,5 \%)$ & $17(31,5 \%)$ & 54 & \\
Pemakaian APD & $10(47,6 \%)$ & $11(52,4 \%)$ & 21 & \\
- Tidak lengkap & & & & \\
- Lengkap & &
\end{tabular}

Tabel 2 menunjukkan bahwa gejala neurotoksik banyak terjadi pada responden yang menggunakan pestisida golongan organofosfat $(74,1 \%)$, dibandingkan dengan jenis pestisida non-organofosfat $(33,3 \%)$. Menurut Steenland risiko dari penggunaan chlorpyrofos (organofosfat) dapat menimbulkan 
defisit saraf yang membuat kecepatan konduksi saraf terganggu sehingga dapat menimbulkan gejala neurotoksik. ${ }^{7,8}$

Hasil uji statistic diperoleh $p$ value sebesar 0,002 $(\mathrm{p}<0,05)$, artinya terdapat hubungan yang bermakna antara jenis pestisida dengan gejala neurotoksik. Penelitian ini selaras dengan penelitian Zainul dimana terdapat hubungan yang bermakna antara jenis pestisida yang digunakan dalam satu kali penyemprotan dengan efek NB $(p$ value $=0,034){ }^{4}$

Kebiasaan petani dalam memilih pestisida yang digunakan kebanyakan hanya berdasarkan pengalaman bertani dan anjuran dari petani lain tanpa memperhatikan efek kesehatan dari pestisida yang digunakan. Petani hanya mengutamakan keberhasilan pestisida dalam membunuh hama tanaman.

Menurut Prijatno, organofosfat merupakan jenis pestisida yang paling toksik. Organofosfat meracuni tubuh dengan menghambat Ach dalam sel darah merah pada sinapsisnya. ${ }^{9}$ Kondisi ini menimbulkan penumpukan Ach sehingga Ach berikatan dengan reseptor muskarinik dan nikotinik pada sistem saraf pusat dan perifer. Kejadian berulang dalam waktu lama sangat beresiko menimbulkan terjadinya gangguan neurotoksik. ${ }^{2}$

Penggantian penggunaan jenis pestisida golongan organofosfat ke pestisida golongan lain yang tidak beracun terhadap manusia seperti golongan piretroid merupakan solusi yang sangat tepat untuk mencegah timbulnya gejala neurotoksik pada petani penyemprot. ${ }^{10}$

\section{Hubungan Komposisi Pestisida dengan Gangguan Neurotoksik}

Tabel 2 menunjukkan bahwa gejala neurotoksik lebih banyak terjadi pada responden yang menggunakan pestisida secara campuran (70,8\%) dibandingkan dengan responden yang menggunakan pestisida secara tunggal $(10,0 \%)$.

Hasil uji statistik diperoleh $p$ value sebesar 0,000 $(\mathrm{p}<0,05)$, artinya terdapat hubungan yang bermakna antara komposisi pestisida dengan timbulnya gejala neurotoksik. Hasil ini sejalan dengan penelitian Afriyanto mengenai kajian keracunan pestisida pada petani penyemprot tanaman cabe di desa candi Kabupaten Bandungan yang menyatakan ada hubungan yang bermakna antara komposisi pestisida yang digunakan dengan kadar kholinesterase darah.

Penyemprotan tanaman sayuran dan Holtikultura di daerah ini biasanya terdiri dari insektisida, fungisida, dan bahan perekat. Penyemprotan seperti ini dapat membahayakan para petani apabila tidak memperhatikan kaidah yang ditentukan. Pada umumnya petani mencampur lebih dari 3 jenis pestisida untuk satu kali penyemprotan, mereka melakukan penyemprotan seperti ini untuk menghemat waktu dan tenaga. Sedangkan anjuran dari Dinas Pertanian penyemprotan untuk satu jenis pestisida dilakukan dalam satu kali penyemprotan baru kemudian dilanjutkan dengan penyemprotan pestisida lainnya. ${ }^{10}$

Banyaknya jenis pestisida yang digunakan petani, menyebabkan beragamnnya paparan pestisida pada tubuh petani yang mengakibatkan pestisida tersebut persisten didalam tubuh. Untuk mengatasi permasalahan tersebut maka sangat perlu dilakukan penyuluhan pertanian tentang tata cara aplikasi pestisida yang benar guna untuk menambah pengetahuan petani agar petani dapat menerapkan teknik aplikasi pestisida secara benar sehingga gangguan kesehatan hingga gejala neurotoksik dapat dihindari.

\section{Hubungan Pemakaian APD dengan Gangguan Neurotoksik}

Tabel 4 menunjukkan bahwa gejala neurotoksik lebih banyak terjadi pada responden yang menggunakan APD tidak lengkap (68,5\%) dibandingkan dengan responden yang menggunakan APD secara lengkap (47,6\%). Namun, hasil uji statistik diperoleh $p$ value sebesar 0,157 ( $\mathrm{p}>0,05)$, artinya tidak terdapat hubungan yang bermakna antara pemakain APD dengan gejala neurotoksik. Penelitian ini sejalan dengan penelitian Edi Supriyana yang menyatakan bahwa tidak terdapat hubungan yang bermakna antara perilaku APD dengan timbulnya gangguan memori jangka pendek. ${ }^{7}$

Penelitian ini tidak bermakna secara statistik disebabkan karena petani tidak menggunakan APD secara lengkap pada saat proses peracikan dan penyemprotan pestisida serta pencucian peralatan. Beberapa petani yang menggunakan APD lengkap seperti sarung tangan dan masker hanya menggunakannya pada saat penyemprotan ataupun pada saat peracikan pestisida saja. APD jenis sarung tangan tidak digunakan petani pada saat penyemprotan karena dianggap mengurangi kenyamanan dan dapat mengganggu proses penyemprotan, kemudian pada saat kegiatan peracikan kebanyakan petani juga tidak menggunakan masker karena beranggapan penggunaan masker ini hanya penting saat melakukan kegiatan penyemprotan saja.

Perilaku petani dalam menggunakan pestisida inilah yang menyebabkan tidak adanya perbedaan gejala neurotoksik pada petani yang menggunakan APD secara lengkap dengan petani yang memakai APD tidak lengkap. Untuk menangani masalah tersebut, maka perlu dilakukannya kegiatan penyuluhan pertanian dan penyuluhan kesehatan dari Dinas Pertanian, dan Dinas Kesehatan agar dapat meningkatkan pengetahuan dan kesadaran petani terutama dalam pemakaian APD pada saat menggunakan pestisida.

\section{SIMPULAN}

Penelitian ini menemukan lebih dari separuh petani penyemprot tanaman sayuran dengan pestisida di Kenagarian Alahan Panjang Kabupaten Solok 
mengalami gejala neurotoksik. Jenis dan komposisi pestisida berhubungan dengan gangguan neurotoksik, sementara pemakaian alat pelindung diri tidak berhubungan secara statistik dengan gangguan neurotoksik.

Disarankan kepada pemerintah daerah Kabupaten Solok untuk menggiatkan kegiatan penyuluhan/pelatihan pertanian tentang aplikasi pestisida yang berisikan materi tentang tata cara pencampuran pestisida, tata cara penyemprotan, fungsi penggunaan APD, serta bahaya penggunaan pestisida.

\section{DAFTAR PUSTAKA}

1. Kementerian Pertanian. Pedoman Teknis Kajian Pestisida Terdaftar dan Beredar: Direktorat Pupuk dan Pestisida Kementerian Pertanian; 2012.

2. Neurotoxicity Identifiying and Controlling Poisons of the Nervous System. US Congress; Washington, DC: Goverment Printing Oficce; 1990.

3. Perveen F. Insecticides-Advances In Integrated Pest Management. Crotihia: In Tech; 2011.

4. Fadillah Z. Efek Nurobehavioral dan Faktor Determinannya Pada Petani Penyemprot Tanaman Sayuran dengan Pestisida di Desa Perbawati Kabupaten Sukabumi. Jakarta: Universitas Syarif Hidayatullah; 2013.
5. National Academy of Sciences (NAS). Gulf War and Health. Washington DC: The National Academies Press; 2003.

6. Wasseling C, Keifer M, Ahlbom A, McConnell R, Moon J, Rosenstock L. Long-term Neurobehavioral Effects Of Mild Poisonings with Organophospate and n-Methyl Carbamate Pesticides among Banana Workers. International Journal Occuptional and Environment Health 2002, 8(1): p. 27-34.

7. Starks SE. Neurological outcomes among pesticide applicators [Dissertation]: University of Lowa;2010.

8. Supriyana E. Hubungan kadar kholinesterase darah dan faktor-faktor lain dengan gangguan memori jangka pendek pada petani padi di satu Kecamatan Kabupaten Bekasi. Depok: Universitas Indonesia; 2010.

9. Djojosumarto P. Pestisida dan aplikasinya. ke-1 E, editor. Jakarta Selatan: PT Agromedia Pustaka; 2008.

10. Afriyanto. Kajian Keracunan Pestisida Pada Petani Penyemprot Cabe di Desa Candi Kabupaten Bandungan Kabupaten Semarang. Semarang: UNDIP; 2008 